\title{
Oral findings in chronic kidney disease: implications for management in developing countries
}

\author{
Elijah O Oyetola ${ }^{1 * \dagger}$, Foluso J Owotade ${ }^{2 \dagger}$, Gbemisola A Agbelusi ${ }^{3 \dagger}$, Olawumi A Fatusi ${ }^{2 \dagger}$ and Abubarkar A Sanusi ${ }^{4}$
}

\begin{abstract}
Background: The importance of oral health care in the management of patients with systemic diseases including chronic kidney disease (CKD) has been affirmed. Many CKD patients have related oral lesions, however, attention to oral health care has been lacking, especially in the developing countries with higher burden of renal diseases.

Methods: One hundred and eighty patients, 90 cases and 90 controls were recruited, interviewed and examined. Oral mucosa assessment was based on the WHO Guide to Epidemiology and Diagnosis of Oral Mucosal Diseases. Urinalysis and blood creatinine levels were determined. Glomerular filtration rate (GFR) of each patient was calculated from the blood creatinine using Cockcroft and Gault formula.

Results: Oral lesions were present in 86 out of 90 (96.5\%) CKD patients compared with 15 out of 90 (16.7\%) controls $(p<0.001)$. Abnormal lip hyperpigmentation was the most frequently seen lesion in 81 out of 90 (90\%) CKD patients. Other significant findings were gum bleeding, xerostomia, candidiasis, burning mouth and abnormal taste. In the controls (without CKD), the mean GFR was lower in subjects with oral lesions compared with those without oral lesions $\mathrm{p}<0.001$.

Conclusions: CKD and reduced GFR in subjects without CKD are risk factors for oral lesions. The higher prevalence of oral lesions in CKD patients necessitates mandatory oral screening to identify patients with deteriorating renal function. The management of such lesions will enhance the overall well-being of CKD patients in developing countries.
\end{abstract}

Keywords: Oral lesions, Chronic kidney disease, Abnormal lip hyperpigmentation, Gum bleeding

\section{Background}

The mouth is a powerful diagnostic tool in the clinical assessment of systemic health [1]. Peculiar oral findings have been reported in diseases such as Human Immunodeficiency Virus (HIV) infection where unusual oral lesions have aided the diagnosis of HIV infection among routine dental patients [2]. Other diseases where oral manifestations may play a vital role in the diagnosis and management include diabetes mellitus [3], coronary heart disease [4], graft versus host disease [5] and chronic kidney disease [6].

Generally, the reported oral lesions in systemic illness include periodontitis, white patches, red patches,

\footnotetext{
* Correspondence: Phemyhoye12@yahoo.com

${ }^{\dagger}$ Equal contributors

'Department of Preventive and Community Dentistry, Obafemi Awolowo

University Teaching Hospitals Complex, lle Ife, Osun State, Nigeria

Full list of author information is available at the end of the article
}

mucositis, oral candidiasis, burning sensation, changes in salivary composition and flow rates, pale mucosa and abnormal pigmentation [6,7]. The presence of these specific oral lesions is not only helpful in detecting underlying systemic diseases but may also indicate the severity of such systemic diseases [8]. In addition, significant improvement in systemic health has been reported following the treatment of associated oral lesions $[6,8]$.

Chronic kidney disease (CKD) like many other systemic diseases, have associated oral problems arising from the disease process or the effects of therapy or both. Consequently, untreated oral lesions may worsen the clinical presentation and prognosis [8]. The National Kidney Foundation (NKF) defined chronic kidney disease as kidney damage for three or more months associated with structural or functional abnormalities of the 
kidney, with or without decreased glomerular filtration rate (GFR) [9]. Furthermore, CKD is a public health problem with a high impact on quality of life [10]. CKD incidence is 337 per million in United States of America and 95 per million populations in United Kingdom [11]. In Nigeria, the incidence is $1.8-10 \%(1,800-10,000$ per million population) and it represents $27.17 \%$ of all medical outpatients' clinic attendance. CKD is therefore regarded as one of the major public health problems in Nigeria [12].

CKD is associated with clinical and radiographic changes in the mouth $[6,11]$. The radiographic changes include loss of lamina dura, maxillary and mandibular radiolucent lesions [11]. The clinical findings in CKD patients are essentially as stated for oral lesions in systemic disease [6]. Unfortunately, attention to the oral aspects has been lacking despite the many merits associated 13]. High graft rejection rate (in kidney transplant patients) [13] and increase in systemic inflammatory burden which worsen the underlying systemic disease [8] are consequences of untreated oral lesions in CKD.

The cause effect relationship between oral infections and systemic diseases is yet to be fully established; however significant improvement in the underlying systemic diseases has been reported following treatment of associated oral lesions [14]. This is a pointer to the importance of oral health care in the management of systemic diseases. In the developed countries, there are guidelines for oral health care in patients with systemic diseases [15]. The reverse is the case in the developing countries where inadequate attention has been given to oral health care needs in this group of patients and this has further worsened the prognosis of the underlying disease [13]. Poor dental awareness among the patients and some medical colleagues are contributory factors [16].

This study investigated oral lesions in CKD in our environment and the association with renal function impairment. An oral health care protocol for the management of CKD patients was also suggested.

\section{Methods}

\section{Study design}

The study was a case control study comparing oral lesions in CKD patients attending the renal clinic of the Obafemi Awolowo University Teaching Hospitals Complex, Ile Ife, Nigeria with controls from the General Medical Outpatient Clinic between September 2011 and March 2012.

\section{Subjects}

The study group consisted of patients diagnosed with chronic renal failure and end stage renal disease. This group was randomly selected from the pool of CKD patients being managed by the Renal Unit of the Obafemi
Awolowo University Teaching Hospital Complex, Ile-Ife, Nigeria. Subjects selected were 18 years and above with no co-morbid medical conditions like diabetes mellitus and primary hypertension as well as negative history of cigarette and alcohol consumption.

The control group comprised clinically healthy subjects who visited the general out-patient department (GOPD) of the hospital on account of pre-employment, pre-admission and routine medical checkup. Control subjects were recruited if they had normal estimated glomerular filtration rate (eGFR) (GFR above $120 \mathrm{ml} /$ min per $1.73 \mathrm{~m}^{2}$ surface area). The GFR was estimated using the Cockcroft and Gault equation [17]. Other inclusion criteria for control subjects were negative history of kidney disease or other chronic debilitating illnesses, cigarette smoking or alcohol consumption.

\section{Ethical issues}

Ethical clearance was obtained from the Ethics and Research committee (ERC), Obafemi Awolowo University Teaching Hospitals Complex, Ile-Ife.

\section{Sample size estimation}

Xerostomia, previously estimated to be $20 \%$ prevalent in the adult population was used to estimate the sample size [18]. With alpha set at $5 \%$, power at $90 \%$ and prevalence of xerostomia projected to be $45 \%$ in renal patients as reported by De la Rosa et al. [19], 80 subjects were required in each group.

\section{Data collection}

Patients who met the inclusion criteria were informed about the study after which a signed consent was obtained. Information on patients' biodata, relevant medical history, drug history, alcohol and tobacco consumption was recorded in addition to the blood pressure and weight of subjects.

Detailed extra oral and intraoral examination was done, and organoleptic method was used to assess halitosis. Oral mucosa assessment was based on the WHO Guide to Epidemiology and Diagnosis of Oral Mucosal Diseases [20].

\section{Periodontal health assessment}

Oral hygiene was assessed using Greene and Vermilion oral hygiene index [21]. Generally, a tooth is said to have developed periodontitis when there is an established pocket of more than $3 \mathrm{~mm}$ depth [22]. For this study, teeth with established pocket more than $3 \mathrm{~mm}$ were described as positive for periodontitis. Periodontal pocket was measured with the Magil ' $\mathrm{O}$ ' periodontal probe which has marking at $3 \mathrm{~mm}$ point from the tip and thus making it easier to pick subjects with periodontics (periodontitis in this study is set at a pocket of $3 \mathrm{~mm}$ and 
above), it is also a readily available periodontal probe [23].

\section{Gingival status}

Gingival status was assessed using gingival index of Loe H (1967) [24].

\section{Salivary measurements}

Objective salivary measurements (unstimulated whole saliva (UWS) and stimulated whole saliva (SWS) was done using spitting method [25].

All the examination/measurements were carried out by one author (Oral Medicine Specialist) after prior calibration. The first twenty patients were examined by two senior specialists. The inter examiner consistency was determined with Kappa statistics. The Kappa coefficient for this study was 0.91 which was found to be appropriate [26].

\section{Assessment of renal function}

Urinalysis was done for each patient using Combic $9^{\circ}$ and blood creatinine was determined from which the estimated GFR of each subject was calculated using Cockcroft and Gault equation [17], as follows:

Estimated creatinine clearance $(\mathrm{ml} / \mathrm{min})=(140$-age $) \mathrm{X}$ body weight $72 \mathrm{X} \mathrm{P}_{\mathrm{cr}}(\mathrm{mg} / \mathrm{dl})$

For female subjects, the gender correlating factor was applied [17].

\section{Statistical analysis}

Descriptive statistics, bivariate analysis such as $t$-test, Fisher's exact and chi-square statistics or their nonparametric equivalents were used as appropriate to compare the two groups. Multivariable logistic regression was used to determine the predictors of oral lesions. Data analysis was done using Stata 11 statistical software (Statacorp, College Station, Texas) and statistical significance was inferred at $\mathrm{p}<0.05$.

\section{Results}

\section{Distribution of the subjects}

One hundred and eighty subjects participated in the study, $108(60 \%)$ males and $72(40 \%)$ females. Average age of the subjects was $47.73 \pm 16.08$ years and majorities $(96.7 \%)$ of the subjects were of Yoruba ethnicity (Table 1).

\section{Oral soft tissue lesion}

Abnormal lip pigmentation was the most frequent lesion seen in CKD subjects, seen 81 out of 90 CKD subjects (90\%). Other significant lesions seen include candidiasis, pale mucosa, petechial hemorrhage and periodontitis (Table 2).
Table 1 Sociodemographic factors and oral complaints

\begin{tabular}{|c|c|c|c|c|}
\hline Characteristics & $\begin{array}{l}\text { All } \\
n=180\end{array}$ & $\begin{array}{l}\text { CKD } \\
n=90\end{array}$ & $\begin{array}{l}\text { Controls } \\
\mathrm{n}=90\end{array}$ & $\begin{array}{l}p \\
\text { value }\end{array}$ \\
\hline Average age (SD) & $47.73(16.1)$ & $50.39(15.3)$ & $45.18(16.5)$ & \\
\hline \multicolumn{5}{|l|}{ Sex } \\
\hline Male & $108(60)$ & $63(58)$ & $45(42)$ & \\
\hline Female & $72(40$ & $27(37.5)$ & $45(62.5)$ & $<0.001^{*}$ \\
\hline \multicolumn{5}{|l|}{ Ethnicity } \\
\hline Yoruba & & $87(96.7)$ & $82(91.1)$ & \\
\hline Hausa & & $1(1.1)$ & $1(1.1)$ & \\
\hline Ibo & & $7(7.8)$ & $2(2.2)$ & 0.064 \\
\hline \multicolumn{5}{|l|}{ Oral lesions [n (\%)] } \\
\hline Present & $102(56.7)$ & $87(96.7)$ & $15(16.7)$ & \\
\hline Absent & $78(43.3$ & $3(3.3)$ & 75 (83.3) & $<0.001^{*}$ \\
\hline Burning mouth $[\mathrm{n}(\%)]$ & $16(8.9)$ & & & \\
\hline Present & & $16(18)$ & $0(0)$ & $<0.001^{*}$ \\
\hline Absent & & $74(82)$ & $90(100)$ & \\
\hline Abnormal taste $[\mathrm{n}(\%)]$ & $24(13.3)$ & & & \\
\hline Present & & $23(26)$ & $1(1)$ & $<0.001^{*}$ \\
\hline Absent & & $67(74)$ & $89(99)$ & \\
\hline Bleeding gums [n (\%)] & $22(12)$ & & & \\
\hline Present & & $21(23)$ & $1(1)$ & \\
\hline Absent & & $69(77)$ & 89 (99) & $<0.001^{*}$ \\
\hline Halitosis & $12(7)$ & & & \\
\hline Present & & $11(12)$ & $1(1)$ & \\
\hline Absent & & 79(88) & 89 (99) & 0.005 \\
\hline Xerostomia & $13(7.2)$ & & & \\
\hline Present & & $11(2)$ & $2(2)$ & \\
\hline Absent & & 79 (88) & 88 (98) & 0.018 \\
\hline
\end{tabular}

Fisher's exact, *statistically significant.

\section{Glomerular filtration rate and presence of oral lesions}

A positive relationship was found between the estimated GFR and oral lesions in cases and in controls, and this was statistically significant as shown in the Table 3.

\section{Mean GFR and oral lesions in CKD subjects}

In this study, aphthous ulcers were seen in CKD subjects with high mean GFR $\left(57.6 \mathrm{ml} / \mathrm{min}\right.$ per $1.73 \mathrm{~m}^{2}$ surface area) unlike oral candidiasis which was seen in subjects with low mean GFR( $35.5 \mathrm{ml} / \mathrm{min}$ per $1.73 \mathrm{~m}^{2}$ surface area). Other lesions seen at a significantly lower mean GFR are: xerostomia, halitosis and abnormal lip pigmentation seen in subjects with mean GFR of 38.6 $\mathrm{ml} / \mathrm{min}$ per $1.73 \mathrm{~m}^{2}$ surface area, $39.7 \mathrm{ml} / \mathrm{min}$ per 1.73 $\mathrm{m}^{2}$ surface area and $49.7 \mathrm{ml} / \mathrm{min}$ per $1.73 \mathrm{~m}^{2}$ surface area respectively. 
Table 2 Oral soft tissue lesions

\begin{tabular}{|c|c|c|c|c|}
\hline \multirow[t]{2}{*}{ Characteristics } & \multirow{2}{*}{$\begin{array}{l}\text { All } \\
n=180\end{array}$} & \multirow{2}{*}{$\begin{array}{l}\text { Cases } \\
\mathrm{n}=90\end{array}$} & \multirow{2}{*}{$\begin{array}{l}\text { Controls } \\
n=90,50 \%\end{array}$} & \multirow{2}{*}{$\begin{array}{l}p \\
\text { value }\end{array}$} \\
\hline & & & & \\
\hline \multicolumn{5}{|l|}{ Abnormal lip pigmentation [n (\%)] } \\
\hline Present & $86(48)$ & $81(90)$ & $5(6)$ & $<0.001^{*}$ \\
\hline Absent & & $9(10)$ & $85(94 \%)$ & \\
\hline Oral Candida infection [n (\%)] & $15(8.3)$ & & & \\
\hline Present & & $14(15.5)$ & $1(1)$ & $<0.001^{*}$ \\
\hline Absent & & $76(84.5)$ & $89(99)$ & \\
\hline Macroglossia [n (\%)] & $2(1)$ & & & \\
\hline Present & & $2(2)$ & $0(0)$ & \\
\hline Absent & & $88(98)$ & $90(100)$ & 0.497 \\
\hline Depapillated tongue [n (\%)] & $3(1.7)$ & & & \\
\hline Present & & $3(3.3)$ & $1(1)$ & \\
\hline Absent & & $87(96.6)$ & $89(99)$ & 0.246 \\
\hline Petechial haemorrhage [n (\%)] & $10(5.6)$ & & & \\
\hline Present & & $10(11.1)$ & $0(0)$ & $<0.001^{*}$ \\
\hline Absent & & $80(89.9)$ & $90(100)$ & \\
\hline Hyperpigmented mucosa & $12(7)$ & & & \\
\hline Present & & $11(12)$ & $1(1)$ & \\
\hline Absent & & $79(88)$ & $89(99)$ & $0.005^{*}$ \\
\hline Aphthous ulcers [n (\%)] & $2(1.11)$ & & & \\
\hline Present & & $2(2)$ & $0(0)$ & \\
\hline Absent & & $78(88)$ & $90(100)$ & 0.247 \\
\hline Pale mucosa [n (\%)] & $22(12)$ & & & \\
\hline Present & & $22(24)$ & $0(0)$ & \\
\hline Absent & & $68(76)$ & $90(100)$ & $0.004^{*}$ \\
\hline Hyperemic mucosa [n (\%)] & $13(7.2)$ & & & \\
\hline Present & & $13(14.4)$ & $0(0)$ & \\
\hline Absent & & $77(85.6)$ & $90(100)$ & $<0.001^{*}$ \\
\hline Gingivitis [n (\%)] & $175(97.2 \%)$ & & & \\
\hline Present & & $88(97.7)$ & $86(95.5)$ & \\
\hline Absent & & $2(2.3)$ & $4(3.5)$ & 1.000 \\
\hline Periodontitis [n (\%)] & $57(31.2)$ & & & \\
\hline Present & & $47(52)$ & $10(11.1)$ & \\
\hline Absent & & $43(48)$ & $80(88.1)$ & $<0.01^{*}$ \\
\hline Gingivae recession [n (\%)] & 39 (21.6) & & & \\
\hline Present & & $35(38.9)$ & $4(4.4)$ & \\
\hline Absent & & $55(61.1)$ & 86 (95.6) & $<0.01$ \\
\hline
\end{tabular}

Fisher's exact, *statistically significant.

\section{Relationship between oral lesions and blood urea concentration in renal patients}

The mean blood urea concentration in CKD patients with oral lesions $(9.4 \mathrm{mmol} / \mathrm{L})$ was higher compared with those without oral lesions $(5.1 \mathrm{mmol} / \mathrm{L})$ although the difference was not statistically significant $\mathrm{P}=0.08$. Blood urea nitrogen was highest in patients with oral candidiasis $(12.5 \mathrm{~mm} / \mathrm{L})$ followed by those with halitosis $(12.1 \mathrm{mmol} / \mathrm{L})$, xerostomia $(11.6 \mathrm{mmol} / \mathrm{L})$, pale mucosa $(11.1 \mathrm{mmol} / \mathrm{L})$ and periodontitis $(9.4 \mathrm{mmol} / \mathrm{L})$.

\section{Regression analysis}

Table 4 shows the association between chronic kidney disease and development of oral lesions after adjusting 
Table 3 Glomerular filtration rate and presence of oral lesions

\begin{tabular}{lccc}
\hline & GFR of Subjects with oral lesions (ml/min) & GFR of subjects without oral lesions (ml/min) & P.value \\
\hline CKD subjects & $49.7 \pm 22.4$ & $77.7 \pm 45.3$ & $<0.01^{*}$ \\
Control & $109.5 \pm 20.6$ & $113.5 \pm 17.7$ & $<0.01^{*}$ \\
All subjects (Cases and control combined) & $58.5 \pm 30.6$ & $112.2 \pm 20.1$ & $<0.01^{*}$ \\
\hline
\end{tabular}

${ }^{*}$ - test with unequal variances.

for age and sex. The likelihood of developing oral lesions was significantly higher in subjects with CKD compared with controls (Odds ratio 153.3, 95\% C.I (40.1-584.8), $\mathrm{p}<0.001)$. Age and sex did not have a significant relationship with the likelihood of developing oral lesion.

\section{Discussion}

Oral lesions were present in 87 of 90 subjects with CKD, representing a prevalence of $97 \%$. This is consistent with studies from different parts of the world excluding Africa that reported up to $90 \%$ of CKD patients showing oral symptoms in the course of their kidney disease $[11,27]$. In some reports, prevalence of oral lesions in CKD was 100\% [6]. Oral lesions are usually due to restricted diets, malnutrition, mouth neglect, immunosuppression and the effects of medications and ureamic toxins on the oral tissues [11]. CKD patients on hemodialysis have also been found to be associated with reduced dental visits which further worsen the oral care [28]. The high prevalence in this study may be attributed to the peculiarity of patients' presentation and local factors that affect the choice of the treatment options affordable in this part of the world. Most Nigerians present late to health facilities and oftentimes would have tried various forms of alternative medicine like spiritual and traditional/native healers before presenting to a health facility $[12,29]$. This late presentation is due to ignorance and poor accessibility and affordability of health care services [30]. Majority of patients, therefore, present at late stages when oral lesions were more likely prevalent. Oral lesions were more prevalent in males (64\%) and this is consistent with other reports who attributed this to the predilection of CKD for males [11]. Oral lesions (pathologic conditions in the mouth), oral signs (abnormalities of oral mucosa found on clinical oral examinations) and oral complaints

Table 4 Role of chronic kidney disease on development of oral lesions

\begin{tabular}{lllll}
\hline Covariate & Odds ratio & Standard error & $\mathbf{9 5 \% ~ C l}$ & $\mathbf{p}$ value \\
\hline CKD & 153.5 & 104.3 & $40.5-581.4$ & $<0.001^{*}$ \\
Age & 1.03 & 0.17 & $1.0-1.06$ & 0.45 \\
Sex (Male) & 0.93 & $0.33-2.6$ & $0.33-2.63$ & 0.89 \\
\hline
\end{tabular}

*Statistically significant, Hosmer-Lemeshow goodness of fit test $p=0.1914$. (described by patients) are the various terms used in describing the oral aspects of kidney disease in the literature [31].

Abnormal lip pigmentation, the most prevalent oral lesion observed in our CKD patients was not commonly reported among renal patients in the earlier studies $[11,27]$. Oral and cutaneous hyperpigmentation in renal patients is due to inability of the kidney to excrete excess beta melanocyte stimulating hormone (b-MSH), the accumulation of which results in the stimulation of melanocyte at the basal layer of oral epithelium [32]. The possible reasons for the high frequency of hyperpigmentation in our environment may be due to the abuse of traditional or orthodox drugs for the treatment of kidney disease or other diseases. These drugs which include antimalarials (quinacrine, chloroquine, hydroxychloroquine) may stimulate melanin secretion and are easily accessible in our environment [33]. In addition, these drugs which are also known to induce hypermelanosis are frequently used by these patients before presentation. Genetic factors (black race) and hot climate associated with constant exposure of the melanocytes to sunlight may also hasten hyperpigmentation. Consequently, abnormal lip and face pigmentation constitutes a great aesthetic challenge to renal patients [34].

Abnormal taste has been commonly reported and was present in $23(26 \%)$ of the CKD subjects [11,35]. The mechanisms underlying alterations in taste perception in uremia patients are unknown, but are probably attributable to influences of ureamic toxins on the central nervous system (CNS) and the peripheral nervous system (the taste receptors) [36]. Bleeding gum was seen in 23 out of 90 (26\%) CKD subjects and has been attributed to poor oral hygiene, ginigival/periodontal inflammation and bleeding abnormalities [37]. Similarly, burning mouth sensation which was significantly higher in CKD patients (16\%) was a consistent finding in many other studies. It was attributed to effects of dry mouth, damage to peripheral nerves by the ureamic toxins and effects of medication [11,38].

In CKD, there is usually fluid restriction, electrolyte imbalance, and use of medications, such as frusemide and hydrochlorothiazide. These may contribute to the complaint of a dry mouth seen in $12.22 \%$ of the renal patients in our study. Other researchers documented a much higher prevalence of $48.2 \%$ [39] and 32.9\% [40]. 
The higher values in studies conducted outside sub Saharan Africa may be due to the primary aetiology of kidney disease in these regions. The aetiological factors in these regions such as diabetes mellitus, hypertension, amyloidosis and autoimmune disease not only cause renal disease but also initiate salivary gland disease independently [12]. In Africans, the commonest aetiology of renal disease is glomerulonephritis which usually results from infections [29]. The complaint of halitosis was significantly higher in CKD patients $(12 \%)$ and has been attributed to dry mouth, poor oral hygiene and ureamic smell [11].

The lower mean stimulated and unstimulated salivary production found in CKD patients $(2.34 \mathrm{ml} / 5 \mathrm{~min}$ and $4.07 \mathrm{ml} / 5 \mathrm{~min})$ when compared to the controls $(3.82 \mathrm{ml} /$ $5 \mathrm{~min}$ and $8.05 \mathrm{ml} / 5 \mathrm{~min}$ ) was consistent with majority of earlier studies [11,41,42]. This finding is similar to that of Kho and colleagues [40] who reported $0.44+$ $0.29 \mathrm{ml} / \mathrm{min}$ and $1.5+0.5 \mathrm{ml} / \mathrm{min}$ for unstipulated whole salivary (UWS) flow rate in renal patients and controls respectively. Reduced salivary flow rate is a consistent finding in CKD patients and it has been reported that reduce flow is due to effects of drugs, emotional stress and neuropathy in CKD patients [43].

Oral candidiasis was more prevalent in CKD cases and may be due to immune suppression from malnutrition, restricted diets, anaemia, stress, and immunosuppressive drugs. Result of this study was consistent with the findings of Al-Mohaya [44] and colleagues who reported 15.5\%, and De la Rosa-Garcia [45] (18.8\%). However these studies were carried out among post-renal transplant chronic kidney disease patients. Considering a higher prevalence of oral candidiasis (37\%) reported by Royne and colleagues [46] and lower prevalence of 5.7\% reported by Gavalda and co-workers [47], oral candidiasis appears to be a consistent finding in patients with chronic kidney disease [11,27]. Late presentation of patients, environmental factors and possibly genetic variations may account for the little variation between our study and the above mentioned studies.

Gingival swelling, described by Proctor and colleagues [11] and Al-Mohaya and co-workers [44] as the commonest oral manifestation of renal disease was not observed in this study despite the prevalent poor oral hygiene. Gum swellings arise from use of medications such as nifedipine, cyclosporine and tacrolimus $[6,11,44]$. These drugs are not routinely used in the management of renal cases in our hospital. The drugs used in our hospital are lisinopril and amlodipine for the treatment of hypertension in renal patients with other supportive drugs. These drugs (lisinopril and amlodipine), unlike nifedipine and cyclosporine, are not associated with gum swellings. Furthermore, most of our patients cannot afford the cost of renal transplantation, a peculiar problem in this environment and developing nations [29]. Such patients (which constitute the majority) are placed on palliative management consisting of the pharmacodietary approach, without the need for immune suppressant drugs that may predispose to gingival swelling.

\section{Glomerular filtration rate and oral findings}

Majority of the studies reported a GFR range of 90-120 $\mathrm{ml} / 1.73 \mathrm{~m}^{2}$ surface area as normal for an adult, with lower values indicating poor renal function $[6,17,37]$. It

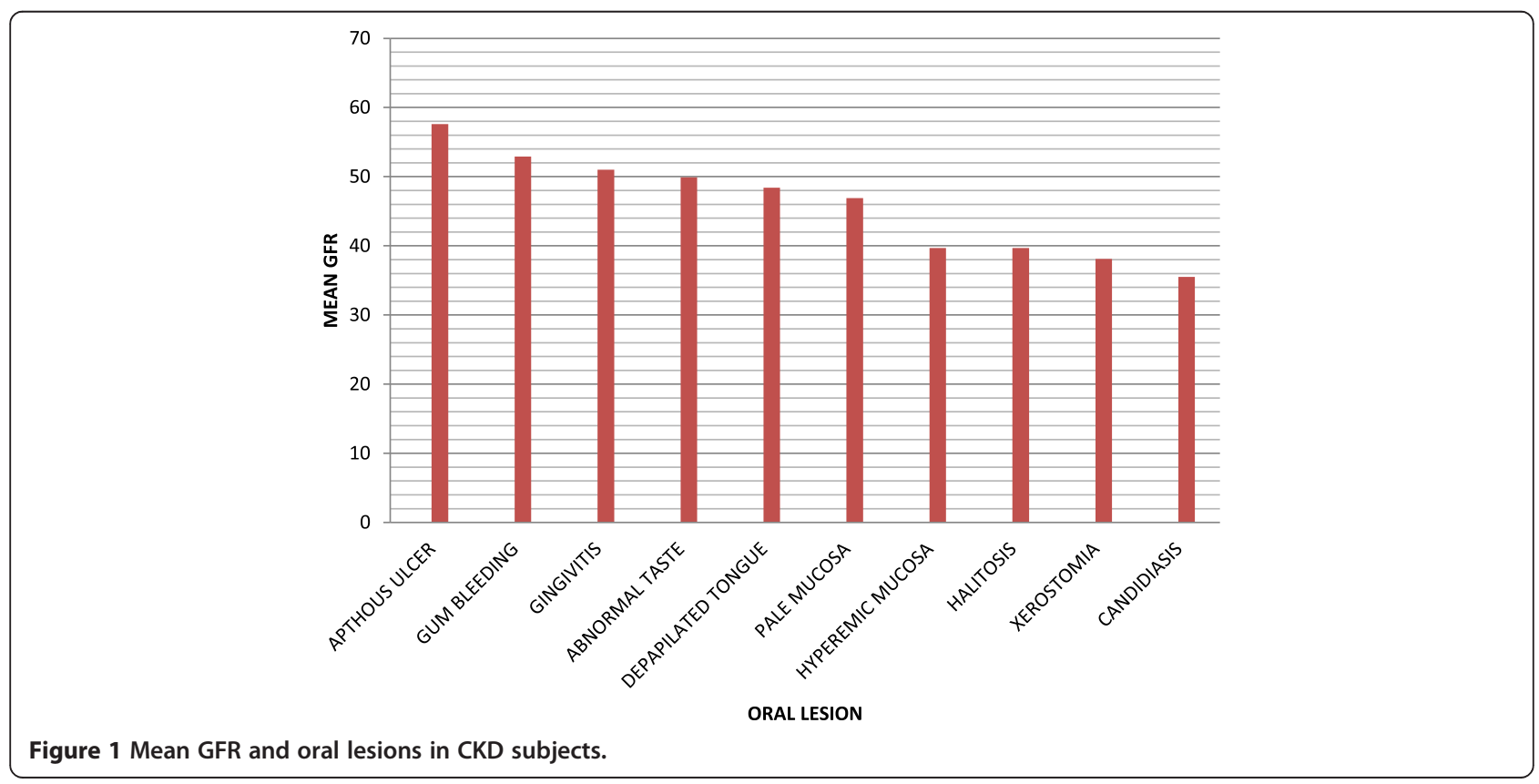


was observed that the mean GFR of subjects with oral lesions was significantly lower than mean GFR of those without oral lesion $\mathrm{p}<0.001$, showing a strong relationship between presence of oral lesions and reduction in GFR especially in CKD subjects. Systemic inflammation arising from oral infection could have an effect on microvasculature of heart and kidney $[4,6]$. The possible establishment of bi-directional relationship between oral infection such as between periodontitis and heart disease has also been postulated between oral lesion and kidney disease $[6,8]$. This probably explains the lower mean GFR in CKD subjects with oral lesions when compared with a relatively higher mean GFR in CKD subjects without oral lesions.

\section{Conclusion}

The prevalence of oral lesions was higher in CKD subjects than in controls and the difference was statistically significant. Abnormal lip pigmentation, halitosis, periodontitis and candidiasis are some of the oral lesions seen. The presence of oral lesions was also associated with reduced GFR in both CKD and control subjects. The positive association between the presence of oral lesions and reduced GFR in healthy/control subjects is a pointer to the possible role(s) of oral lesions in the initiation and/or progression of renal disease.

In addition, this study showed the possibility of using presence of oral lesions to predict the severity of underlying renal problem as shown in Figure 1 where the relationship between the mean GFR and oral lesions were clearly shown. While the presence of oral candidiasis (seen in subjects very low GFR) may indicate a state of severe renal impairments, the presence of lesions like aphthous ulcer may reflect a just mild to moderate renal disease since they are usually seen at slightly below normal GFR.

Sequel to the impact of oral aspect of CKD in the quality of life of patients, it is therefore recommended that all patients with chronic kidney disease will benefit from dental care; therefore, they should be routinely evaluated for oral lesion(s) and treated accordingly. Likewise, dental evaluation and appropriate dental treatments should be given to all prospective kidney transplant patients before transplantation as well as regular review after the transplantation. More importantly, there is need for a closer relationship between nephrologists and dentists in the management of chronic renal patients so as to ensure optimal quality of life at all times.

\section{Abbreviations}

CKD: Chronic Kidney Disease; GFR: Glomerular filtration rate; HIV: Human Immunodeficiency Virus; NKF: National Kidney Foundation.

\section{Competing interests}

The authors declare that they have no competing interests.

\section{Authors' contributions}

OEO was involved in conception of the idea, drafting the manuscript and in data collection. OFJ did the analysis, interpretation of data and gave the final approval of the version to be published. AGA revised the manuscript for important intellectual content. FAO participated in the study design and data analysis. SSA also helped with revision of the manuscript and assessment of patients with chronic kidney disease. All authors read and approved the final manuscript.

\section{Acknowledgement}

The authors express appreciation to Dr. Andy Wolf for proofreading the manuscript.

\section{Author details}

${ }^{1}$ Department of Preventive and Community Dentistry, Obafemi Awolowo University Teaching Hospitals Complex, lle Ife, Osun State, Nigeria.

${ }^{2}$ Department of Oral and Maxillofacial Surgery and Oral Pathology, Obafemi Awolowo University Teaching Hospitals Complex, lle Ife, Osun State, Nigeria. ${ }^{3}$ Department of Preventive Dentistry, Lagos University Teaching Hospital, IdiAraba, Lagos State, Nigeria. ${ }^{4}$ Department of Internal Medicine, Obafemi

Awolowo University Teaching Hospitals Complex, Ile Ife, Osun State, Nigeria.

Received: 19 September 2014 Accepted: 29 January 2015

Published online: 20 February 2015

\section{References}

1. Mishra MN. Mouth mirrors systemic diseases. Indian J Public Health Res Dev. 2012;3:83-6.

2. Agbelusi G, Wright A. Oral lesions as indicators of HIV infections among routine dental patients in Lagos, Nigeria. Oral Dis. 2005;11:370-3.

3. Nassar PO, Poleto R, Salvador CS, Felipetti FA, Nassar CA. One-stage fullmouth disinfection and basic periodontal treatment in patients with diabetes mellitus. J Public Health. 2014;22:81-6.

4. Thomopoulos C, Tsioufis C, Soldatos N, Kasiakogias A, Stefanadis C. Periodontitis and coronary artery disease: a questioned association between periodontal and vascular plaques. Am J Cardiovasc. 2011;1:76-83.

5. Granitto M, Fall-Dickson J, Norton C, Sanders C. Review of therapies for the treatment of oral chronic graft-versus-host disease. Clin J Oncol Nurs. 2014;18:76-81.

6. Patil S, Khandelwal S, Doni B, Rahman F, Kaswan S. Oral manifestations in chronic renal failure patients attending two hospitals in North Karnataka, India. OHDM. 2012;11:100-6.

7. Tadakamadla J, Kumar S, Mamatha G. Comparative evaluation of oral health status of chronic kidney disease (CKD) patients in various stages and healthy controls. Spec Care Dentist. 2014;34:122-6.

8. Wahid A, Chaudhry S, Ehsan A, Butt S, Ali Khan A. Bidirectional relationship between chronic kidney disease \& periodontal disease. Pak J Med Sci. 2013;29:211-5

9. Levey A, Eckkardt K, Tsukamoto Y, Levin A, Coresh J, Rossert J, et al. Definition and classification of chronic kidney disease; a position statement from kidney disease improving global outcome. Kidney Int. 2005:67:2089-100.

10. Levey A, Coresh J, Balk E, Kausz A, Levin A, Steffes M, et al. National foundation practice guidelines for kidney disease, evaluation, classification and stratification. Classification and Stratification Ann Intern Med. 2003;139:137-47.

11. Proctor R, Kumar N, Stein A, Moles D, Porter S. Oral and dental aspect of chronic renal failure. J Dent Res. 2005:84:199-208.

12. Ulasi I, Chinwuba K. The enormity of chronic Renal Disease in Nigeria. The situation in a teaching Hospital in South-East Nigeria. Journal of Tropical Medicine volume 2010 Article ID 501957, 6 pages doi: 101155/2010/501957

13. Zwiech R, Bruzda-Zwiech A. Does oral health contribute to post-transplant complications in kidney allograft recipients? Acta Odontol Scand. 2013;71:756-63.

14. Peter BL, Ann FB, Panos NP, Olusegun O, Maurizio T, Matthew EL, et al. Periodontal disease and atherosclerotic vascular disease: does the evidence support an independent association? a scientific statement from the American heart association. Circulation. 2012;125:2520-44.

15. Kumar J, Samelson R. Oral health care during pregnancy: recommendations for oral health professionals. N Y State Dent J. 2009;75:29-33. 
16. Sarumathi T, Saravanakumar B, Datta M, Nagarathnam T. Awareness and knowledge of common oral diseases among primary care physicians. J Clin Diagn Res. 2013;7:768-71.

17. Amira C. Assessment of glomerular filtration rate in clinical practice in Nigeria. Medical Practionner. 2007;52:76-81.

18. Keles M, Tozoglu U, Uyanik A, Eltas A, Bayindir Y, Cetinkaya R, et al. Does peritoneal dialysis affect halitosis in patients with end-stage renal disease? Perit Dial Int. 2011;31:168-72.

19. De la Rosa GE, Mondragon P, Aranda RS, Bustamante, Ramirez M. Oral mucosa symptoms, signs and lesions in end stage renal disease and non end stage renal disease diabetic patients. Oral Patol Oral Cir Bucal. 2006;11:E467-467.

20. Kramer I, Pindborg J, Bezroukov V, Sardo JS. Guide to epidemiology and diagnosis of oral mucosal diseases and conditions. Community Dent Oral Epidemiol. 1980;8:1-24.

21. Greene J, Vermillion J. The oral hygiene index; a method for classifying oral hygiene status. J Amer Dent Association. 1960;60:29-35.

22. Armitage G. Diagnosis of periodontal diseases. J Periodontol. 2004;74:1237-47.

23. Srinivas SR, Dhoom SM, Nagarajappa S, Vidya B, Janardhan A. Periodontal probing systems: a review of available equipment. Compedium. 2011;32:71-7.

24. Loe $H$. The gingival index, the plaque index and the retention index systems. J Periodontol. 1967;38(6):610-6.

25. Navazesh M, Kumar SK. Measuring salivary flow challenges and opportunities. J Am Dent Assoc. 2008;139:355-405.

26. Sim J, Wright C. The kappa statistics in reliability studies: use, interpretation, and sample size requirements. Physical Theraphy. 2005;85:257-9.

27. Saini R, Sugandha, Saini S. The importance of oral health in kidney Disease. Saudi J Kidney Dis Transplant. 2010;21:1151-2.

28. Xie T, Yang Z, Dai G, Yan K, Tian Y, Zhao D, et al. Evaluation of the oral health status in Chinese hemodialysis patients. Hemodial Int. 2014;18:668-73.

29. Arogundade F, Sanusi A, Hassan M, Akinsola A. The pattern, clinical characteristics and outcome of ESRD in Ile-lfe, Nigeria: Is there a change in trend? African Health Sciences 2011. 2011:11:594-601.

30. Alebiosu C, Ayodele O, Abbas A, Olutoyin A. Chronic renal failure at the Olabisi Onabanjo University Teaching Hospital, Sagamu, Nigeria. Afr Health Sci. 2006:6:132-8.

31. Popovska M, Spasovski G, Orovcanec N, Cekovska S, Simonceva M, BexetiZendeli L, et al. Oral findings in end-stage renal disease. Prilozi. 2013;34:85-92

32. Kauzman A, Pavone M, Bradley G. Pigmented lesion of the oral cavity; review, differential diagnosis and case presentation. J Can DentAssoc. 2004; $70: 682-3$

33. Dereure O. Drug induced skin pigmentation: epidemiology, diagnosis and treatment. Am J Clin Dermatol. 2001;2:253-62.

34. Pico M, Lugo-Somolinos A. Cutaneous alterations in patients with chronic renal failure. Int J Dermatol. 1992;31:860-3.

35. Hamid M, Dummer C, Pinto L. Systemic conditions, oral findings and dental management of renal failure patients; General considerations and case report. Braz Dent. 2006;17:166-70.

36. Bolton C, Young G. Uremic neuropathy. In: Neurological complications of renal disease. Boston: Butterworth; 1990. p. 76-6.

37. Ruospo M, Palmer S, Craig J, Gentile G, Johnson D, Ford P, et al. Prevalence and severity of oral disease in adults with chronic kidney disease: a systematic review of observational studies. Nephrol Dial Transplant. 2014;29:364-275.

38. Leao JC, Alcino LM, Airton GV, Segundo L, Carvalho AAT, Barrett W, et al. Uremic stomitits in chronic renal failure. CLINICS. 2005;60:259-62.

39. Hajheydari Z, Makhlough A. Cutaneous and mucosa manifestations in patients on maintenance hemodialysis. Astudy of 101 patients in Sari. Iran J Kidney Dis. 2008:2:86-90.

40. Kho H, Lee S, Chung S, Kim Y. Oral manifestations and salivary flow rate, PH, and buffer capacity in patients with end-stage renal disease undergoing haemodialysis. Oral Surg Oral Med Oral Pathol. 1999;88:316-9.

41. Kao C, Hsieh J, Tsai S, Ho Y, Chang H. Decreased salivary function in patients with end stage renal disease requiring hemodialysis. Am J Kidney Dis. 2000;36:1110-4.

42. Epstein S, Mandel I, Scopp I. Salivary composition and calculus formation in patients undergoing hemodialysis. J Periodontol. 1980;51:336-8.

43. Porter S, Hegarty A, Scully C. An update of the etiology and management of xerostomia. Oral Surg Oral Med Oral Pathol Oral Radiol Endod. 2004:97:28-46.
44. Al-Mohaya M, Darwazeh A, Bin-Salih S, Al-Khudair W. Oral lesions in Saudi Renal transplant patients. Saudi J Kidney Dis Transpl. 2009;20:20-9.

45. Dela R-GE, Mondragon-Padilla A, Irigoyen- Gnacho M, Bustamante-Raminex M. Oral lesions in a group of kidney transplant patients. Med Oral Patol Oral Cir Buccal. 2005;10:196-204.

46. Royne T, Martin N, Britta H. Prevalence and early detection of fungi infection; A cross sectional controlled study in a group of Swedish end stage renal disease patients. Scand J Urol Nephrol. 2009;43:325-30.

47. Gavalda C, Bagan J, Scully C, Silvester F, Milian M, Jimenez Y. Renal hemodialysis patient; oral, salivary, dental and periodontal findings in 105 adult cases. Oral Dis. 1999;5:299-302.

\section{Submit your next manuscript to BioMed Central and take full advantage of:}

- Convenient online submission

- Thorough peer review

- No space constraints or color figure charges

- Immediate publication on acceptance

- Inclusion in PubMed, CAS, Scopus and Google Scholar

- Research which is freely available for redistribution 